\title{
Article
}

\section{'Knowing the places of care': How nurses facilitate transition of children with complex health care needs from hospital to home}

Carter, Bernie, Bray, Lucy, Sanders, Caroline Diane, Van Miert, Clare, Hunt, Anne and Moore, Andrew

Available at http://clok.uclan.ac.uk/20451/

Carter, Bernie ORCID: 0000-0001-5226-9878, Bray, Lucy, Sanders, Caroline Diane ORCID: 0000-0003-3240-538X, Van Miert, Clare, Hunt, Anne and Moore, Andrew (2016) 'Knowing the places of care': How nurses facilitate transition of children with complex health care needs from hospital to home.

Comprehensive Child and Adolescent Nursing, 39 (2). pp. 139-153. ISSN 24694193

It is advisable to refer to the publisher's version if you intend to cite from the work.

http://dx.doi.org/10.3109/01460862.2015.1134721

For more information about UCLan's research in this area go to http://www.uclan.ac.uk/researchgroups/ and search for <name of research Group>.

For information about Research generally at UCLan please go to http://www.uclan.ac.uk/research/

All outputs in CLoK are protected by Intellectual Property Rights law, including Copyright law. Copyright, IPR and Moral Rights for the works on this site are retained by the individual authors and/or other copyright owners. Terms and conditions for use of this material are defined in the policies page. 


\title{
'Knowing the places of care': How nurses facilitate transition of children with complex health care needs from hospital to home.
}

\begin{abstract}
The number of children with complex health care needs continues to rise and they often have prolonged hospital stays with their discharge home being delayed by a range of factors, despite the fact that, except in extraordinary circumstances, a child's home is the most appropriate place for them to receive long-term care. The aim of this appreciative, qualitative interview-based study was to explore the work of nurses whose main role is supporting children and families move from an institutional place of care to long-term care within the family home. Analysis of interview transcripts was collaborative, interpretive and thematic. Forty-six participants ( 9 nurses and 37 local stakeholders) engaged in the study. Findings reflect the ways in which the nurses facilitated transition of children with complex needs from hospital to home and the journeys the nurses took to develop the skills, knowledge and networks needed to support this transition. 'Knowing the places of care' was fundamental to success of the nurses' work. As the nurses' knowledge of the places (and processes) of care deepened, they were better able to act as informed guides to families and other professionals and to improve care. The nurses' practice was driven by the belief that the place where care occurs matters. Home was seen as a transformative and sustaining place where caring practices could become incorporated into an environment in which the family could exist and be nurtured together.
\end{abstract}

\section{Key words}

at-homeness, child, complex health care needs, discharge planning, home, places and spaces of care, nurse, WellChild

\section{Introduction}

The number of children with complex chronic health care needs continues to rise (Cohen and Patel, 2014) and children with complex health care needs require high levels of treatment and care. This diverse group of children account for both a high proportion of hospitalisations (Coller, Nelson, Sklansky, Saenz et al. 2014) and prolonged periods of hospitalisations due to a variety of challenges in the child being discharged home. Protracted discharge exposes children to the psychosocial and 
physical harms associated with hospitalisation (Noyes, Brenner, Fox \& Guerin, 2014) and it is generally accepted that it is better for children to be cared for at home (Wang and Barnard, 2008). The discipline of health geography has added to our understanding of the importance of the place of care (Milligan and Wiles, 2010), including the home (Williams 2002). Health geography also contributes to our understanding of how the structures and practices of care are influenced by the places and spaces in which care is delivered (Heath, Greenfield \& Redwood, 2015). Where people are cared for influences their experiences of care and their sense of who they are (Moore, Carter, Hunt \& Sheikh, 2013). It has long been accepted that, except in extraordinary circumstances, a child's home is the most appropriate place for the child to receive long-term care. The child's home is a place where, with the right support, the child and their family is most likely to feel comfortable and where they can experience what Seamon (1979) describes as "at-homeness".

However, the discharge process (hospital to home) for children with complex health care needs can be challenging (Brenner, Larkin, Hilliard, Cawley et al., 2015; Noyes et al., 2014). Once home, maintaining family life and the child's participation in everyday life can also be difficult (Woodgate, Edwards \& Ripat, 2012). Although many parents report the experience of caring for their child as being rewarding, (Carnevale, Alexander, Davis, Rennick, \& Troini, 2006), for many families the presence of health technology in the home is intrusive and challenges the family's sense of control and familiarity (Moore et al., 2010). The meaning of both home and care is altered (Wang \& Barnard, 2008). Parental identity can be challenged as parents fulfil dual responsibilities as both parent and carer/nurse (Moran, Delany \& Spittle, 2015). Family life and former routines are disrupted as new, often more challenging routines, become embedded, whilst parents become anxious (Caicedo, 2015) and deprived of sleep (Angelhoff, Edéll-Gustafsson \& Mörelius, 2015, McCann, Bull, \& Winzenberg, 2015): In addition, strain on family finances can be caused by both loss of income (Kogan, Strickland \& Newacheck, 2009) and additional costs (Bourke-Taylor, Howie \& Law, 2014) resulting from their child's medical needs. Effectively managing the different transitions that the families face in getting and keeping their child at home is integral to promoting the families' sense of control and their experience of effective care. This experience can be supported through robust discharge planning and continuity of care between the hospital and home (Zanello, Calugi, Rucci, 
Pieri et al., 2015), clear communication between all those involved in meeting the child's and family's needs (Noyes et al., 2014) and partnership between nurses and other professionals (Looman, Presler, Erickson, Garwick et al., 2013; Petitgout, Pelzer, McConkey \& Hanrahan, 2012).

Recognising that wherever possible care is 'better at home', WellChild - a national UK charity for sick children - implemented the WellChild Children's Nurse Programme (WCCNP) in 2006. Their primary focus is on supporting families who have a child with complex health care needs and specifically to supporting transition home from hospital. Each WellChild Children's Nurse (WCCN) works in partnership with a host health care organisation that employs them via charitable funding.

As part of an evaluation of the service commissioned by the charity, this paper examines the work of the WCCNs from the perspectives of the WCCNs and the stakeholders with whom they liaised in supporting the families assigned to their caseloads. It focuses on the work they undertook in supporting the children and families' move from an institutional place of care (the acute hospital setting) to a very different place of care - the family home.

\section{Methodology and Methods}

The study used a qualitative approach which drew on the participatory and affirmative principles of Appreciative Inquiry (AI) (Cooperrider \& Whitney, 1999). AI, an approach with its roots in action research, is increasingly used in health-care settings (Carter, 2006; Richer, Ritchie \& Marchionni, 2010) as it aims to reveal positive changes and what is working well within settings. AI was selected for this study as it was hoped that examples of best practice could be identified and ultimately shared across the network of WCCNs.

\section{Methods}

Face-to-face interviews were undertaken with the WCCNs (currently in practice or within 6 months of leaving post) at their place of work or other mutually acceptable location. The interviews focused on the work they undertook, the solutions they generated to the challenges they encountered in their practice, and successes achieved in facilitating effective transition home. Interviews were selected as the preferred method as they provided the opportunity to generate rich dialogic data. With the participants' informed consent these interviews were audio-recorded. In addition, semi-structured 
telephone interviews were undertaken with professional stakeholders with whom the WCCNs worked and liaised; these interviews were either audio-recorded or field-notes were taken. The questions to stakeholders mirrored those asked of the nurses and were primarily narrative, e.g., 'From your perspective how does 'WCCN's name' influence/support your role?'

The study received ethics approval from the Faculty of Health Ethics Committee at the University of Central Lancashire.

\section{Data Analysis}

Data from the interviews were transcribed and subjected to thematic analysis (Attride-Stirling, 2001): codes were assigned to statements, words and sections of the text and then grouped into areas of similarity (sub-themes), and the subthemes then grouped into core themes with an encompassing meta-theme providing a final synthesis. Initially each transcript was analysed individually, then the WCCN transcripts were considered as a dataset and the same was done for the stakeholder transcripts. A cross case analysis was conducted within each data to identify common and divergent concepts, followed by a comparison between the datasets, and a final synthesis. Each member of the research team contributed to data analysis by generating codes, impressions and insights which were discussed in analytical meetings until consensus was reached; our approach was reflexive, iterative and collaborative.

\section{Findings}

Within the findings we present a brief overview of the participants' demographics before then presenting the meta-theme and three core themes and the six sub-themes. Anonymised quotations reported in the paper are identified as being from a ' $\mathrm{WCCN}$ ' or by the disciplinary background of a stakeholder. The findings reflect the dynamic work of the WCCNs as seen from both the perspectives of the WCCNs and the stakeholders.

\section{Demographics}

Nine WCCNs (8 female, 1 male) with length of service with WellChild from four months to 
nearly three years agreed to participate. Five were employed within a community setting (in-reach service to hospital) and four within a hospital setting (out-reach service to the community). Some were new to their geographical setting whilst others knew it well. Thirty-seven stakeholders, representative of the people with whom the nurses liaised were interviewed. The stakeholders were mainly experienced professionals including Nurse Managers, Social Workers, Paediatricians, Therapists, Specialist Nurses, Health Visitors, and Clinical Pyschologists.

\section{Knowing the places of care}

'Knowing the places of care' encompasses the aspirations and accomplishments of the nurses as they gained skills and knowledge about the work of transition and discharge. This sense of 'knowing' was achieved through the journeys they took through different places of care such as hospital, community and home. 'Knowing the places of care' took the nurses time to achieve. This 'knowing and involved the nurses not only being physically present within the different places of care but also establishing and sustaining a presence with the different stakeholders across these places of care. Both the nurses and the stakeholders described 'knowing' as fundamental to supporting transition and discharge home and to effectively sustaining the child and family at home. The stakeholders tended to work almost exclusively within one type of setting - an institution (e.g., hospital or hospice) or the community (e.g., clinics or home), while the nurses had to get to know many different institutional and community settings. The three-stage journey the nurses undertook to develop their knowledge of the different places in which they supported the child and their family is described under the three core themes: embarking, embedding and flourishing (see Table 1). Their depth of knowledge increased from a more superficial knowledge in 'embarking' to a much deeper knowledge by the time they had moved from 'embedding' to 'flourishing'. 


\begin{tabular}{|c|c|c|c|}
\hline Meta theme & Core theme & Description & Sub themes \\
\hline \multirow{3}{*}{$\begin{array}{l}\text { Knowing the } \\
\text { places of care }\end{array}$} & Embarking & $\begin{array}{l}\text { Embarking describes the } \\
\text { starting points of the } \\
\text { nurses' journeys as they } \\
\text { were taken into new or only } \\
\text { partly explored places of } \\
\text { care and how they } \\
\text { established a sense of } \\
\text { belonging. }\end{array}$ & $\begin{array}{l}-\quad \text { Early days for the nurses } \\
-\quad \text { Having a base and a sense of } \\
\text { belonging }\end{array}$ \\
\hline & Embedding & $\begin{array}{l}\text { Embedding describes the } \\
\text { challenges and } \\
\text { achievements of the nurses } \\
\text { as they gained an intimate } \\
\text { insight into the places of } \\
\text { care they were working in } \\
\text { and started to embed } \\
\text { change. }\end{array}$ & $\begin{array}{ll} & \text { Becoming established } \\
\text { - } & \text { Communicating, relating and } \\
& \text { networking }\end{array}$ \\
\hline & Flourishing & $\begin{array}{l}\text { Flourishing describes how } \\
\text { the nurses' practice thrived } \\
\text { and they were able to make } \\
\text { change happen and became } \\
\text { expert guides. }\end{array}$ & $\begin{array}{l}\text { - } \quad \text { Driving change forward } \\
\text { - Knowing these places really } \\
\text { well }\end{array}$ \\
\hline
\end{tabular}

\section{Embarking}

Embarking describes 'beginnings': the starting points of the nurses' journeys into new or only partly explored landscapes of care.

\section{Early days}

Both the nurses and the stakeholders reported that it took between three and six months for the nurse to settle into their new role, build their caseload, and "get to grips with things". Each nurse brought a variety of experience to what they perceived to be an exciting opportunity to build or develop pathways and policies that would result in improved discharge planning for children with complex needs. Those with previous experience of working in community roles found this helped their transition, as one nurse explained:

"I had quite a good grounding before I started so I sort of hit the ground running" $(W C C N)$

For those whose experience had primarily been within an acute setting, they needed to adjust 
their acute-oriented knowledge and skills to community practice and, for some "coming back into a hospital environment was a real challenge" (WCCN). Both the nurses and the stakeholders

emphasised that establishing an insider role within both community and acute settings was essential to the nurses ability to navigate both landscapes of care in an informed manner.

All of the nurses, especially those working in a geographical area new to them, experienced an initial sense of being overwhelmed by the perceived enormity of the challenge that their new role presented, as one explained:

“...working out exactly how I was going to meet those challenges and make a difference and have some influence, it was all very mind-blowing" (WCCN).

Some nurses experienced a sense of isolation as they struggled to find a place for their new role within their organisation. This involved "persistent groundwork" and taking time to try and make sense of the existing operational systems and structures (the organisational geography) of their own and other settings. This process of adjustment and familiarisation incorporated a consideration of the contextualised social, political and institutional influences on the local structures and provision of care and the resources available. The stakeholders described how they supported this process of familiarisation by sharing their knowledge of their own particular organisation and place of care. Developing an insider's sense of familiarity was essential when negotiating with organisations to achieve the child's/family's desired outcome, that of going home.

Regardless of their experience and relational skills, most of the nurses experienced some opposition and a degree of hostility from some professionals who seemed to be 'threatened' by their role. As one stakeholder, a consultant paediatrician explained:

"Initially there was some hostility from the hospital... some people felt [WCCN] was a threat or a reflection of them not doing their work well but this has mostly been overcome now" (Consultant Paediatrician, Hospital).

The nurses countered instances of hostility by adopting a pragmatic, resilient approach. One nurses explained how she worked:

"softly, softly at the beginning. I just kind of felt the water a little bit, went to meetings, ...ward rounds, ...did a bit of teaching... let them get to know me" (WCCN). 
Bringing about change and understanding required a "solution orientation" and "saying [we] need to collaborate". Sometimes the nurses let issues settle down before trying to move forward. To an extent this meant working in a mediation role, bridging the gap in the political landscapes between 'them and us'; most notably old rivalries between some staff in acute and community settings. While these tensions existed for some of the nurses, others talked of both acute and community settings being "positively welcoming” to them as a co-worker.

\section{Having a base and a sense of belonging}

Operating between diverse settings meant that the nurses had to be adaptable and able to create a sense that they belonged: this was most quickly developed in the main office space from which they worked (e.g., hospital or community setting) and where they felt their presence was most legitimate. Developing this sense of belonging was supported when they also had a physical base in their secondary setting from which to "set up shop" and the assets (e.g., swipe cards, phone) to support a legitimate presence. Without these assets the nurses reported that they felt more "like a visitor...than part of the team" and that this constrained their insider status and practice, as one explained:

“...I was trying to find a little home, as in a desk or something, I hadn't got a manager there [hospital] and it seems that you have to have a manager there to be recognised in a way.... have a manger here [community] but without 'home' you can't really influence things in the hospital" (WCCN).

Some of the stakeholders were equally aware of these tensions and were active in their efforts to minimise difficulties for the nurses and to reassure other professionals involved in the child's care: "she [nurse] needs to be able to be as at home in the hospital and the community. The 'honorary contract' took a bit of a fight before it was sorted but she can now move freely wherever she needs to go. Seems silly but it took effort to make it happen" (Nurse Manager, Hospital).

\section{Embedding}

Embedding focuses on the challenges to and achievements of the nurses as they further established themselves within their role and deepened their knowledge of the varied places they were 
working within and across.

\section{Becoming established}

Early challenges were balanced by achievements where the nurses worked with families who had been "desperate for help". Their success was predicated on their ability to know the settings, provide guidance and act as a form of organizing 'glue'. This involved holding together disparate agencies, reducing tensions, establishing relationships, providing care in different settings, getting people "singing from the same song sheet" and establishing a sense of direction for discharge planning. One stakeholder explained the new sense of cohesion that the nurse had achieved: "[We've now got] cohesion of services, communication is at the fore and [WCCN's name is] bringing all services together for MDT's [multi-disciplinary teams]. [It was] previously very hard to bring all these layers together effectively... we now have a 'hub' for those families and the process is less 'bitty"' (Consultant Paediatrician, Community).

By bringing their knowledge and direction to disparate services the nurses were able to "add a lot of purpose into these [discharge planning] meetings" (Nurse Manager, Hospital). A community based stakeholder explained how the nurse's knowledge of different places and settings means the nurse:

"provides additional insight... made a big difference... and been the catalyst in getting [children and families] home and getting support" (Social Worker, Community).

Implementing change to support effective discharge home was complex and demanding work and few of the nurses were fully prepared either for the depth of understanding they needed to have about the different and disparate settings and services or:

"the unbelievable amount of work that goes into discharge planning meetings and leading and co-ordinating discharge planning” (WCCN).

The nurses described how making progress involved them knowing the settings so that they could influence practice and policy and move discharge planning from being largely invisible into a highly visible and easily understood part of everyday professional practice. Most of the nurses worked with other professionals to develop unifying documentation that created maps and pathways - as a 
way of identifying and then disseminating knowledge about discharge home - for all the stakeholders involved in the supporting a child with complex needs home.

Despite their best efforts, some discharges could still take the nurses months to achieve with some children being 'stuck' in hospital, often thwarted by delays in the care packages being put in place. This resulted in negative financial, social and emotional consequences for families and frustration for all the professionals in a system they could not adequately influence or change. The nurses and the stakeholders were concerned about the harm wrought when a child became "institutionalised" and reported that this should be considered by the people and/or systems they perceived were creating delays. One of the nurses talked of a child who had "literally lived in ICU" for the first 18 months of his life and was:

“... suddenly well and he turned a corner relatively quickly.... [His parents] had to gradually show him the world outside... and then the days really dragged because from their point of view, they had a child who was demanding more, wanted a better experience" $(W C C N)$.

Trying to ensure timely discharge required the nurses to draw on a range of skills and experiences, as one explained:

“... you have some power because you are in a senior role... but it's your relationships and negotiation skills that help you shape the way that services are provided" (WCCN).

Through their persistence and increased sense of 'knowing, the nurses gradually improved the processes surrounding discharge and facilitated smoother transitions home for children and their families.

\section{Communicating, relating and networking}

The embedding of processes was facilitated by the nurses' deepening knowledge, their abilities to establish strong networked relationships, be accepted as a resource and "create bridges between the various settings" (Social Worker). Having the agency to move freely between the hospital and community settings was a huge advantage as stakeholders based in both acute and community settings explained, for example: 
"She [WCCN] understands both sides, the stresses of acute and community and she can relay to both sides...She listens and links and makes life easier. She's made a whole lot of difference. Now we know that the community is part of the team [it's] not them and us" (Therapist, Hospital).

The nurses talked about how they "pulled things together" for families by dedicating time to build in-depth relationships with the families and the stakeholders across a variety of settings. This central advocacy role was underpinned by 'knowing the places of care' and knowing each family's particular circumstances. This embedded knowledge or 'sense of knowing' was often described as their "proudest achievement". As one nurse explained:

"I do love getting to grips with the entire family, the whole set-up, the whole situation, who goes where, who's got the dog... it is so important to know this for liaising with these children ...you can't plan without knowing that stuff"' (WCCN).

Through their in-depth knowledge and their acknowledged credibility they were able to maintain momentum and help to find solutions and develop individually tailored care packages that helped to support family life whilst ensuring that parents retained responsibility for their child.

\section{Flourishing}

Flourishing examines the deepest level of 'knowing' and reflects how the nurses were able to drive positive change forward once they achieved expertise in being able to act as guides to the families and other professionals.

\section{Driving change forward}

As their knowledge deepened, their practice flourished and the nurses were able to drive forward change and improve the quality of the processes supporting children's transition home and transitions between home and other settings (e.g., respite). Through sharing their acquired knowledge and skills, the nurses were also able to affect change by enabling stakeholders to develop a greater insight into each family's strengths and needs. This resulted in care packages, interventions and support to be tailored in a responsive and very supportive way. One stakeholder, an experienced paediatrician explained that: 
"[Now] I have a true sense of understanding of the context of the family that I couldn't get from just asking them questions at the clinic" (Consultant Paediatrician, Hospital)

The nurses also shared their sense of knowing the places and processes of transition care through education and training, for example:

"I've set up training and [this has helped] get the hospices and respite centres on

board.... The training has given their staff confidence" (WCCN).

The knowledge and experience of the nurses, the robustness of their relationships and networks, the local politics, the fluidity of movement between hospital and community settings, and the relational history between other key stakeholders were all influential in terms of what change was possible and the speed at which it could occur.

\section{Knowing these places really well}

Through their daily work, the nurses came to know and understand the psychosocial, material, structural and political factors that influenced the places in which care took place in their locality. The nurses developed a deep sense of belonging to their settings and talked of "knowing these places really well" (WCCN) and understanding of how services worked across the community and hospital settings, as one stakeholder explained:

"She's a bit like a walking encyclopaedia of what's available for the children and families, she 'just knows' who to talk to, where to go, she's absolutely dependable" (Staff Nurse, Hospital)

However, the problem of the nurse being perceived as the expert guide in a setting - the "person who knows everything" - meant that a degree of dependency could result as it was often "difficult to work well when she is away" (Senior Nurse, Community). The nurses talked of having to guard against families becoming dependent on them. Evidence of flourishing practice was most clearly evident through the diffusion of knowledge into practice. Not only did the professionals become increasingly confident about being actively engaged in transition but the families also became more confident and resilient. The nurses supported the families and the professionals to become more knowledgeable about their own landscapes of care; the nurses' 'sense of knowing' became more 
widely shared.

\section{Discussion}

'Knowing the places of care' was something that the nurses aspired to and achieved. They gained skills and knowledge about the work of transition and discharge, and they acquired this sense of 'knowing' through their journeys across different places of care such as hospital, community, respite and home. Their vision was to shift the spatial location of the children's care from a stressful (McCaffrey, 2006), institutional hospital space to the child's home, a more therapeutic family-centred space of care. Being able to plan for a child to 'go home', 'be at home' and 'stay at home' and experience a sense of "at-homeness" (Seamon, 1979) was perceived as being essential for families to feel that they were actually able to be a 'real family' (Carter et al., 2007). The nurses' role was focused on helping families to re-establish a sense of togetherness. Embedding and sustaining a whole systems approach (Department of Health, 2003, 2011) that embodied continuity of care became a reality. Daily practice reinforced the nurses' awareness that co-ordinating discharge and embedding care at home were complex and multi-faceted undertakings that required a deep sense of knowing, as seen in other studies (Noyes et al., 2014).

The nurses were aware that simply getting a child home was not the end of their role: support to families was essential to mitigate the potential deleterious effects on parents' physical and mental health and well-being which could result from care giving (Murphy, Christian, Caplin \& Young, 2007). The nurses invested time in developing strong relationships and connections between the relevant stakeholders and the families to ensure discharge was co-ordinated (Noyes et al., 2014) This helped the family feel supported and secure during the process of discharge home, as also seen in Carter et al. (2007). This type of effort is aligned to the proposition that care can be thought of in terms of "interdependency, reciprocity and multidirectionality" (Milligan \& Wiles 2010, p737). Acknowledging that multi-agency care was crucial to their role, the nurses were aware of the reciprocal interdependence between themselves, the families and the other professionals involved in the shared "production of care" (Fine \& Glendinning 2005, p671).

The journeys taken by the nurses occurred within and across places and spaces of care 
(Milligan, 2000). The nurses moved through different physical spaces (wards and clinics in acute and tertiary care settings, general practitioner surgeries, schools, hospices and respite settings as well as the home); through different organisational and cultural spaces (via interactions with professionals in the NHS, commissioning, social care, education, housing and the voluntary sector), and through different emotional and social spaces (in environments which were challenging and in situations which created uncertainty, happiness and distress). Appreciating the complexity of the work they undertook and the range of places and spaces in which it occurred, provides insight into why some of the nurses' journeys and relationships were more challenging than others.

Even though discharge planning for children with complex needs is not a new venture (Lewis \& Noyes, 2007), the journeys taken by the nurses and other stakeholders were, in many ways' ventures into the unknown. As noted by Noyes et al. (2014) discharge is a complex and longitudinal intervention. A substantive part of the nurses' role was to create a clearer map to guide themselves and other people involved in supporting children to transition home. The nurses were, in this sense, cartographers, accumulating literal and experiential knowledge of spaces and places in which care took place. They developed a clear and extended geographical sense of the towns, villages and communities they served, the resources they could access (specialist teams, portage, play libraries), and they came to understand the relational, physical, existential, political and historical structures and connections between people, spaces and places. As the nurses established this extended territorial knowledge they were developing clearer appreciation of the lives of the families and were able to share this deeper understanding, as appropriate, with other stakeholders. Through facilitative working practices they were able to mediate between the differing customs, practices and assumptions of diverse agencies and settings.

The nurses' role was constrained and facilitated by the people, places, spaces and structures around them (Halford \& Leonard, 2003). They were most effective in their guiding role when they were supported by clear management structures and when the environment was not too hostile and/or where they were able to make alliances (Atkinson, Wilkin, Stott, Doherty, \& Kinder, 2002). 


\section{Limitations and implications for future research}

This study is limited by the fact that it focused on nurses working for a specific charity (WellChild) and the stakeholders with whom they worked. However, these nurses and stakeholders reflected a wide range of geographical settings and places of care thus the findings have wider resonance for the nursing care and support of children and families in their own homes. Whilst reliance on telephone interviews with many of the stakeholders may have reduced the depth of data generated when compared with the face-to-face interviews undertaken with the nurses we did not find this to be the case. The interviews were undertaken at a single time point and a more longitudinal approach could have further deepened our understanding of the journeys taken by the nurses.

Future research needs to consider the ways in which the working practices of the WCCNs can be transferred to other settings that do not have specialist transition support and the ways in which local networks can be best utilised. Future research should consider how best to promote professionalprofessional and family-professional communication, as this is key to sustaining the success of care at home. Ways of sharing the knowledge currently held within different settings should be prioritised.

\section{Conclusion}

The notion that, wherever possible, children should be able to receive care at home was, in essence, the force that underpinned and drove the nurses' everyday work and their acquisition of knowledge. Fundamental to this is the belief that the place where care occurs, matters. Home is more than a physical location - it is a place full of associations and symbolic meanings. It is a place where the caring practices that sustain the child can be incorporated into an environment, which nurtures the child and the family. As the nurses' knowledge of the places (and processes) of care deepened, they were better able to act as informed guides to families and other professionals, able to reduce the fragmentation of care (Looman et al., 2013) and to reduce the challenges faced by families. Even in situations where specialist transition support is not available, nurses and other health and social care professionals could improve the discharge journeys of children through dialogue with colleagues in other settings and placing the child's and family's needs at the centre of care. 


\section{References}

Andrews, G.J. (2004). (Re)thinking the dynamics between healthcare and place: therapeutic geographies in treatment and care practices. Area, 36, 307-318.

Angelhoff, C., Edéll-Gustafsson, U., \& Mörelius, E. (2015). Sleep of parents living with a child receiving hospital-based home care. Nursing Research, 64, 372-380.

Atkinson, M., Wilkin, A., Stott, A., Doherty, P., \& Kinder, K. (2002). Multi-agency working: a detailed study (LGA research report 26), National Foundation for Educational Research.

Attride-Stirling, J. (2001). Thematic networks: an analytic tool for qualitative research. Qualitative Research, 1, 385-405

Brenner, M., Larkin, P. J., Hilliard, C., Cawley, D., Howlin, F., \& Connolly, M. (2015). Parents' perspectives of the transition to home when a child has complex technological health care needs. International Journal of Integrated Care, 15, e035-e035.

Bourke-Taylor, H., Howie, L., \& Law, M. (2010). Impact of caring for a school-aged child with a disability: Understanding mothers' perspectives. Australian Occupational Therapy Journal, 57, 127 136.

Caicedo, C. (2015). Health and functioning of families of children with special health care needs cared for in home care, long-term care, and medical day care settings. Journal of Developmental and Behavioral Pediatrics, 36(5), 352-361.

Carnevale, F.A., Alexander, E., Davis, M., Rennick, J., \& Troini, R. (2006). Daily Living With Distress and Enrichment: The Moral Experience of Families With Ventilator-Assisted Children at Home. Pediatrics, 117, e48-e60.

Carter, B. (2006). 'One expertise among many'-- working appreciatively to make miracles instead of finding problems: Using appreciative inquiry as a way of reframing research. Journal of Research in Nursing, 11, 48-63.

Carter, B., Cummings, J., \& Cooper, L. (2007). An exploration of best practice in multi-agency working and the experiences of families of children with complex health needs. What works well and what needs to be done to improve practice for the future? Journal of Clinical Nursing, 16, 527-539.

Cohen, E., \& Patel, H. (2014). Responding to the rising number of children living with complex chronic 
conditions. CMAJ: Canadian Medical Association Journal, 186, 1199.

Coller, R. J., Nelson, B. B., Sklansky, D. J., Saenz, A. A., Klitzner, T. S., Lerner, C. F., \& Chung, P. J. (2014). Preventing hospitalizations in children with medical complexity: A systematic review. Pediatrics, 134, e1628-e1647.

Cooperrider, D. L. \& Whitney, D. (1999). "Appreciative Inquiry: a positive revolution in change.," In The Change Handbook: Group Methods for Shaping the Future, P. Holman \& T. Devane, eds., San Francisco: Berrett-Koehler Publishers, Inc., pp. 245-261.

Department of Health. (2003.) Discharge from hospital: pathway, process and practice, Department of Health, London.

Department of Health. (2011). NHS at Home: Community Children's Nursing Services, COI, Department of Health.

Fine, M. \& Glendinning, C. (2005). Dependence, independence of inter-dependence? Revisiting the concepts of 'care' and 'dependency'. Ageing \& Society, 25, 601-621.

Halford, S. \& Leonard, P. (2003). Space and place in the construction and performance of gendered nursing identities. Journal of Advanced Nursing, 42, 201-208.

Heath, G., Greenfield, S., \& Redwood, S. (2015). The meaning of 'place' in families' lived experiences of paediatric outpatient care in different settings: A descriptive phenomenological study. Health and Place, 31, 46-53.

Heaton, J., Noyes, J., Sloper, P., \& Shah, R. (2005). Families' experiences of caring for technologydependent children: a temporal perspective. Health \& Social Care in the Community, 13, 441-450.

Kogan, M.D., Strickland, B.B., \& Newacheck, P.W. (2009). Building systems of care: findings from the National Survey of Children With Special Health Care Needs. Pediatrics, 124, Suppl 4, S333-S336.

Lewis, M. \& Noyes, J. (2007). Discharge management for children with complex needs. Paediatric Nursing, 19, 26-30.

Looman W.S., Presler E., Erickson, M.M., Garwick, A.W., Cady, R.G., Kelly, A.M. \& Finkelstein, S.M. (2013). Care Coordination for Children With Complex Special Health Care Needs. Journal of Pediatric Health Care. 27, 293-303.

McCaffrey, C.N. (2006). Major stressors and their effects on the well-being of children with cancer. 
Journal of Pediatric Nursing, 21, 59-66.

McCann, D., Bull, R., \& Winzenberg, T. (2015). Sleep deprivation in parents caring for children with complex needs at home: A mixed methods systematic review. Journal of Family Nursing, 21(1), 86118.

Milligan, C. (2000). 'Bearing the burden': towards a restructured geography of caring. Area, 32, 49-58.

Milligan, C. \& Wiles, J. (2010). Landscapes of care. Progress in Human Geography, 34, 736-754.

Moran, F. C., Delany, C., \& Spittle, A.J. (2015). Lifestyle implications of home mechanical insufflationexsufflation for children with neuromuscular disease and their families. Respiratory Care, 60(7), 967974.

Moore, A.J., Anderson, C., Carter, B., \& Coad, J. (2010). Appropriated landscapes: the intrusion of technology and equipment into the homes and lives of families with a child with complex needs. Journal of Child Health Care, 14, 3-5.

Moore, A., Carter, B., Hunt, A. \& Sheikh, K. (2013). 'I am closer to this place': space, place and notions of home in lived experiences of hospice day care'. Health and Place, 19, 151-8.

Murphy, N.A., Christian, B., Caplin, D.A., \& Young, P.C. (2007). The health of caregivers for children with disabilities: caregiver perspectives. Child: Care, Health \& Development, 33,180-187.

Noyes J., Brenner, M., Fox, P. \& Guerin, A. (2014). Reconceptualizing children's complex discharge with health systems theory: novel integrative review with embedded expert consultation and theory development. Journal of Advanced Nursing, 70, 975-996.

Petitgout, J.M., Pelzer, D.E., McConkey, S.A. \& Hanrahan, K. (2013). Development of a Hospital-Based Care Coordination Program for Children With Special Health Care Needs. Journal of Pediatric Health Care, 27, 419-425.

Richer, M., Ritchie, J., \& Marchionni, C. (2010). Appreciative inquiry in health care. British Journal of Healthcare Management, 16,164-172.

Seamon, D. (1979). A geography of the lifeworld: Movement, rest, and encounter. New York, St Martin's Press.

Wang, K.W.K. \& Barnard, A. (2008). Caregivers' Experiences at Home With a Ventilator-Dependent Child. Qualitative Health Research, 18, 501-508. 
Williams, A. (2002). Changing geographies of care: employing the concept of therapeutic landscapes as a framework in examining home space. Social Science \& Medicine, 55, 141-154.

Woodgate, R.L., Edwards, M. \& Ripat, J. (2012). How families of children with complex care needs participate in everyday life. Social Science \& Medicine, 75, 1912-1920.

Zanello, E., Calugi, S., Rucci, P., Pieri, G., Vandini, S., Faldella, G., \& Fantini, M. P. (2015). Continuity of care in children with special healthcare needs: A qualitative study of family's perspectives. Italian Journal of Pediatrics, 41(1), 1-9 